\title{
¿Evaluation and Comparison of Two Deep Convection Parameterization Schemes at Convection-Permitting Resolution
}

\author{
Xu Zhang, ${ }^{\mathrm{a}, \mathrm{b}}$ Jian-Wen BaO,${ }^{\mathrm{c}}$ BaOde Chen,${ }^{\mathrm{a}, \mathrm{b}}$ And Wei Huang ${ }^{\mathrm{a}, \mathrm{b}}$ \\ a Shanghai Typhoon Institute, China Meteorological Administration, Shanghai, China \\ ${ }^{\mathrm{b}}$ Innovative Center of Regional High Resolution NWP, Shanghai, China \\ ${ }^{\mathrm{c}}$ NOAA/Earth System Research Laboratory, Boulder, Colorado
}

(Manuscript received 5 February 2021, in final form 2 August 2021)

\begin{abstract}
Coarse-grained results from a large-eddy simulation (LES) using the Weather Research and Forecasting (WRF) Model were compared in this study with the WRF simulations at a typical convection-permitting horizontal grid spacing of $3 \mathrm{~km}$ for an idealized case of deep moist convection. The purpose of this comparison is to identify major differences at the subgrid process level between two widely used deep convection parameterization schemes in the WRF Model. It is shown that there are considerable differences in subgrid process representations between the two schemes due to different parameterization formulations and underlying assumptions. The two schemes not only differ in trigger function, subgrid cloud model, and closure assumptions but also disagree with the coarse-grained LES results in terms of vertical mass flux profiles. Thus, it is difficult to discern which scheme is more advantageous over the other at the subgrid process level. The conclusions from this study highlight the importance of establishing benchmarks using observations and LES to develop and evaluate convection parameterization schemes suitable for models at convection-permitting resolution.
\end{abstract}

KEYWORDS: Convective-scale processes; Convective parameterization; Subgrid-scale processes

\section{Introduction}

Many regional operational forecast centers have been running numerical weather prediction (NWP) models with convection-permitting resolutions (horizontal grid size of less than $5 \mathrm{~km}$ ) for short-range weather forecasting. In general, because these models cannot fully resolve individual convective elements (see, e.g., Bryan et al. 2003; Moeng et al. 2010), including parameterization schemes of subgrid convection in the physics configuration is a practical means for them to accurately account for the contribution of unresolved convection to the total cloud and precipitation production in the forecast. Traditionally, the objective of subgrid convection schemes is to describe the ensemble effect of many individual subgrid clouds on resolved dynamics, assuming there is quasi-equilibrium between the large-scale forcing and convective response at subgrid scales (Arakawa and Schubert 1974). At convectionpermitting resolutions, however, this quasi-equilibrium assumption breaks down, and thus subgrid convection schemes are required to be capable of simulating the transient characteristics of convective processes (Gerard 2015). In recent years, some studies proposed more general frameworks to relax the quasi-equilibrium assumptions by using prognostic closures and cloud models (e.g., Gerard and Geleyn 2005).

Arakawa et al. (2011) took a different route to relax the quasi-equilibrium assumption by introducing a factor of a quadratic function of the mesh fraction to scale the quasiequilibrium convective mass flux. For practical uses in NWP

¿ Denotes content that is immediately available upon publication as open access.

Corresponding author: Wei Huang, huangw@typhoon.org.cn models, Arakawa's formulation and new algorithms of mesh fraction have been introduced into quasi-equilibrium convection parameterization schemes that can be used at convectionpermitting resolutions (Grell and Freitas 2014; Han et al. 2017; Kwon and Hong 2017). Bechtold et al. (2008, 2014) and Zheng et al. (2016) used another approach to relax the quasiequilibrium assumption by modifying the convective adjustment time scale. However, these schemes also contain various other assumptions and subgrid-process parameterizations with inherent uncertainty.

Many studies have focused on the sensitivity of the simulation to different convection schemes (e.g., Fowler et al. 2020). However, few studies have been devoted to examining the differences in details in parameterizations and underlying assumptions. Thus, there is a need for the modeling community to tackle the question: what are the fundamental differences in various convection parameterizations that lead to differences in the modeled intensity and evolution of convection? Answering this question will provide insight into the physical understanding of the behavior of a given parameterization. It will also provide useful information about what observations or high-resolution simulations (e.g., cloudresolving modeling or LES) can be used to validate parameterized convective processes.

In this study, coarse-grained LES results are used to evaluate and compare two convection parameterization schemes, which are widely used at convection-permitting resolutions in the Weather Research and Forecast Model (WRF) user community, in terms of detailed aspects (i.e., the trigger, cloud model, and closure), and to provide physical insight into the practical implementation of the parameterization. Despite their popularity, these two schemes were never compared at convectionpermitting resolutions at the process level against LES. The comparison and evaluation of these two schemes using the LES 
results not only reveal the intrinsic uncertainty in their parameterization formulations, but also demonstrate that coarsegrained information from LES can uniquely provide needed information to evaluate the convection schemes at convectionpermitting resolutions at the level of parameterized subgrid processes.

The rest of the paper is organized as follows: section 2 describes the setup of the WRF simulations and LES, the coarsegraining method, and the two subgrid convection schemes investigated in this study. The results from two $3-\mathrm{km}$ simulations with convection parameterization schemes are evaluated and compared against the coarse-grained LES results in terms of the trigger, cloud model, and closure in section 3 . The results are summarized and discussed in section 4 .

\section{WRF Model setup, coarse-graining method, and two convection parameterization schemes}

In this study, idealized simulations of moist deep convection were generated using version 4.1.3 of the Advanced Research WRF Model (WRF-ARW; Skamarock and Klemp 2008). An LES benchmark with a horizontal grid size of $100 \mathrm{~m}$ was generated using the same model to evaluate the performance of the convection parameterization schemes. The Thompson microphysics scheme (Thompson et al. 2004, 2008) was used in the LES, which has five prognostic hydrometeor categories (including graupel) and predicts the number concentrations of rainwater and ice particles. The surface layer scheme and radiation physics are neglected. The model domain is $120 \mathrm{~km} \times 120 \mathrm{~km}$ in the horizontal plane with a vertical extension of $20 \mathrm{~km}$. The simulation was initialized with a sounding that represents an atmospheric environment with moderate instability. The initial profiles of temperature and humidity were the same as those used by Weisman and Klemp (1982). Convection is initiated by a thermal bubble with a $10-\mathrm{km}(1.5 \mathrm{~km})$ horizontal (vertical) radius, and with a potential temperature perturbation ranging from a maximum of $3 \mathrm{~K}$ at the center of the bubble (located at $x=40, y=60$, and $z=1.5 \mathrm{~km}$ ) to zero at the edge of the bubble. The Coriolis effect was turned off, as in Weisman and Rotunno (2000). The vertical spacing was approximately $100 \mathrm{~m}$ (200 levels). Subgrid turbulent mixing was parameterized using the 1.5order 3D prognostic TKE closure (Deardorff 1980). The 100-m LES simulation served as the "truth" against which the coarser simulations with convection parameterization schemes were evaluated.

The benchmark LES fields were coarse-grained and used a box average to obtain the subgrid convective characteristics at coarser resolutions (Honnert et al. 2011; Huang et al. 2018; Zhang et al. 2018). The LES model domain was divided into subdomains with a specified box size $\Delta$ ( $3 \mathrm{~km}$ in this study) for coarse-graining. In this study, if the coarse-graining subdomain encompasses one or more cloudy LES grid points containing cloud water and ice $\left(q_{c}+q_{i}>0\right.$, with $q_{c}$ and $q_{i}$ denoting cloud water and ice mixing ratio, respectively), the subdomain was defined as cloudy and as a statistical sample. The subdomain without any cloudy LES grid point was excluded from the calculation. For a variable $\varphi$, the subgrid convective fluxes at different coarser resolutions of $\Delta$ were computed in each grid box as follows:

$$
{\overline{w^{\prime} \varphi^{\prime}}}^{\Delta}=\overline{\left(w-\bar{w}^{\Delta}\right)\left(\varphi-\bar{\varphi}^{\Delta}\right)^{\Delta}},
$$

where $w$ is the vertical velocity at the LES grid, and the overbar designated by $\Delta$ denotes the horizontal average over the subdomain $\Delta \times \Delta$.

Two scale-adaptive subgrid convection schemes widely used in the WRF user community were evaluated at a $3-\mathrm{km}$ grid resolution. The first is the multiscale Kain-Fritsch (MSKF; Zheng et al. 2016) scheme, which is an updated version of the Kain-Fritsch (KF) convective parameterization (Kain 2004; Kain and Fritsch 1990), with scale-dependent capability. Scaledependent changes included a dynamic adjustment timescale, a modification of lifting condensation level (LCL)-based minimum entrainment rate, and a scale-dependent fallout rate for liquid water and ice condensates. The second convection parameterization is a modified Global Forecast System (GFS) simplified Arakawa-Schubert (SAS) scheme developed by the Korea Institute of Atmospheric Prediction System (KSAS) (Kwon and Hong 2017). The KSAS scheme modifies the magnitude of convective mass flux at the cloud base, the threshold of convective inhibition, and convective detrainment to be functions of the grid-size-dependent convective updraft fraction. The experimental setup was the same as the benchmark LES, except for the horizontal resolution. Because the $3 \mathrm{D}$ prognostic TKE closure was designed for the grid sizes in the inertial subrange and not suitable for convection-permitting grid sizes (Bryan et al. 2003), the Yonsei University (YSU) scheme (Hong et al. 2006) for the planetary boundary layer (PBL) was used to parameterize the subgrid mixing instead of the 3D prognostic TKE closure.

The two convection schemes examined in this study differ in the trigger, cloud model, and closure. A summary of the different characteristics of the two convection parameterization schemes is listed in Table 1 . Note that the $100-\mathrm{m}$ vertical grid spacing used in the $3-\mathrm{km}$ simulations for the convenience of comparisons between the LES and $3-\mathrm{km}$ simulations is not typically used in operational NWP models. To ensure the results of the $3-\mathrm{km}$ simulations using the $100-\mathrm{m}$ vertical grid spacing are relevant to NWP applications, additional $3-\mathrm{km}$ simulations were carried out with a usual configuration of 51 vertical levels often used in NWP applications with enhanced resolution toward the surface (Benjamin et al. 2016). These simulations confirm that the difference between two $3-\mathrm{km}$ simulations with different configurations of vertical levels is not significant enough to change the conclusions of this study (figures not shown).

\section{Results}

This study focuses on the early development of convection to evaluate the performance of these modified convection schemes in representing the transient phase of convection. Therefore, statistical results to be shown were only sampled from the early stages of development (0-30 min) at 1-min intervals.

To evaluate the subgrid convective effect, the conserved variable moist static energy $\left(h=c_{p} T+L q_{v}+g z\right)$ during the 
TABLE 1. Characteristics of different convection schemes.

\begin{tabular}{|c|c|c|}
\hline & MSKF & KSAS \\
\hline Trigger & $\begin{array}{l}\text { Based on temperature perturbation } \\
\text { related to gridscale forcing }\end{array}$ & $\begin{array}{l}\text { Based on the depth between the origination level of a } \\
\text { parcel and its LFC }\end{array}$ \\
\hline Cloud base & LCL of the USL mixture & $\begin{array}{l}\text { LFC (where the condition } h>h^{*} \text { is first met below } \\
\quad 450 \mathrm{hPa} \text { ) }\end{array}$ \\
\hline Cloud top & $\begin{array}{l}\text { The level at which vertical velocity first } \\
\text { becomes negative }\end{array}$ & The first level where parcel buoyancy becomes negative \\
\hline Updraft originating level & $\begin{array}{l}\text { KLCL }-1 \text {, where KLCL is the vertical } \\
\text { index of the LCL }\end{array}$ & The level with largest moist static energy below $700 \mathrm{hPa}$ \\
\hline Updraft entrainment & $\begin{array}{l}\text { All positively buoyant mixtures (i.e., } x< \\
x_{c} \text { ) are entrained into the cloudy updraft }\end{array}$ & $\varepsilon_{u}=\varepsilon_{0}\left(\frac{q_{s}}{q_{s, b}}\right)^{2}+10^{-4}(1-\mathrm{RH})\left(\frac{q_{s}}{q_{s, b}}\right)^{3}$ \\
\hline Updraft detrainment & $\begin{array}{l}\text { All negatively buoyant mixtures (i.e., } \\
\text { mixtures with } x>x_{c} \text { ) will be detrained }\end{array}$ & $\begin{array}{l}\text { The detrainment rate for updraft is same as the } \\
\text { entrainment rate at cloud base } \delta_{u}=\varepsilon_{0}=0.1 / z_{\mathrm{LFC}}\end{array}$ \\
\hline Downdraft originating level & $150 \mathrm{hPa}$ above the top of the USL & The level with minimum moist static energy \\
\hline Downdraft entrainment & $\begin{array}{l}\text { Entrains equal amounts of air from all } \\
\text { model layers within the downdraft } \\
\text { source layer (DSL), which extends from } \\
\text { the origination level to the top of the } \\
\text { USL. Below the top of the USL, there is } \\
\text { no entrainment. }\end{array}$ & $\begin{array}{l}\text { Constant from the downdraft origination to the } \\
\text { surface, } 10^{-4}\end{array}$ \\
\hline Downdraft detrainment & $\begin{array}{l}\text { Within the DSL, there is no detrainment. } \\
\text { Between the top of the USL and the } \\
\text { base of the downdraft, detrainment is a } \\
\text { linear function of pressure. }\end{array}$ & $\begin{array}{l}\text { Downdraft entrainment and detrainment rates are } \\
\text { constants from the downdraft origination to the LFC, } \\
10^{-4} \text {. Between the surface and the LFC } \\
\delta_{d}=\left(1-\beta^{1 / K_{\mathrm{LFC}}}\right) / \overline{\Delta z}, \beta \text { is a constant currently set to } \\
0.05 \text {, implying that only } 5 \% \text { of downdraft mass flux at } \\
\text { LFC reaches the ground surface due to detrainment, } \\
K_{\mathrm{LFC}} \text { is the vertical index of the LFC level, and } \overline{\Delta z} \text { is } \\
\text { the average vertical grid spacing below the LFC. }\end{array}$ \\
\hline Closure & $\begin{array}{l}\text { The quasi-equilibrium CAPE closure in } \\
\text { which at least } 90 \% \text { CAPE is removed } \\
\text { within the convective adjustment time }\end{array}$ & The quasi-equilibrium cloud work function closure \\
\hline
\end{tabular}

moist adiabatic process was used in the analysis, where $T$ and $q_{v}$ are temperature and water vapor mixing ratio, respectively; $c_{p}$ is the heat capacity of air at constant pressure; $L$ is the latent heat of vaporization of liquid water; and $g z$ is geopotential energy. The subgrid convective tendencies from the convection parameterization can be written in the form of $h$ :

$$
\left.\bar{\rho} \frac{\partial \bar{h}}{\partial t}\right|_{\text {subgrid }}=\left.\bar{\rho} c_{p} \frac{\partial \bar{T}}{\partial t}\right|_{\text {subgrid }}+\left.\bar{\rho} L \frac{\partial \bar{q}_{v}}{\partial t}\right|_{\text {subgrid }},
$$

where $\bar{\rho}$ is the mean gridbox air density, and the overbar indicates the mean gridbox value. Two subgrid convective tendency terms on the right-hand sides of Eq. (2) are from the output of the convection parameterization schemes. Only the columns where the convection schemes are activated are sampled. Thus, the parameterized convective tendency can be compared with the tendency calculated from the 3-km coarsegrained LES results using the following:

$$
\left.\bar{\rho} \frac{\partial \bar{h}}{\partial t}\right|_{\text {subgrid }}=-\frac{\partial \bar{\rho} \overline{w^{\prime} h^{\prime}}}{\partial z} .
$$

Note that the subgrid flux on the right-hand side of Eq. (3) does not contain vertical turbulent flux. Following Siebesma and
Cuijpers (1995), the total subgrid flux is decomposed into three terms: the convective mass flux term, the turbulent flux in clouds and the environmental turbulent flux. The subgrid flux on the right-hand side of Eq. (3) is only the convective mass flux term that is usually assumed dominant and parameterized in the convection scheme. The $h$ tendencies due to the resolved motion are also calculated from the MSKF, KSAS runs, and the coarse-grained LES using the following:

$$
\left.\bar{\rho} \frac{\partial \bar{h}}{\partial t}\right|_{\text {resolved }}=-\frac{\partial \bar{\rho} \bar{w} \bar{h}}{\partial z} .
$$

Figure 1a shows the vertical profiles of the parameterized convective tendencies from the MSKF and KSAS schemes [Eq. (2)], and the coarse-grained LES results [Eq. (3)], at 3-km resolution averaged over $0-30 \mathrm{~min}$. The parameterized convective tendencies are mostly negative below $3500 \mathrm{~m}$, mainly caused by convective drying, and positive above $3500 \mathrm{~m}$ caused by convective heating, consistent with the coarse-grained LES results. However, the magnitudes of both parameterized convective tendencies are smaller than those from the coarsegrained LES results. The differences in magnitude and vertical profile of convective tendencies in the two convection schemes result from different closure formulations and cloud models. 

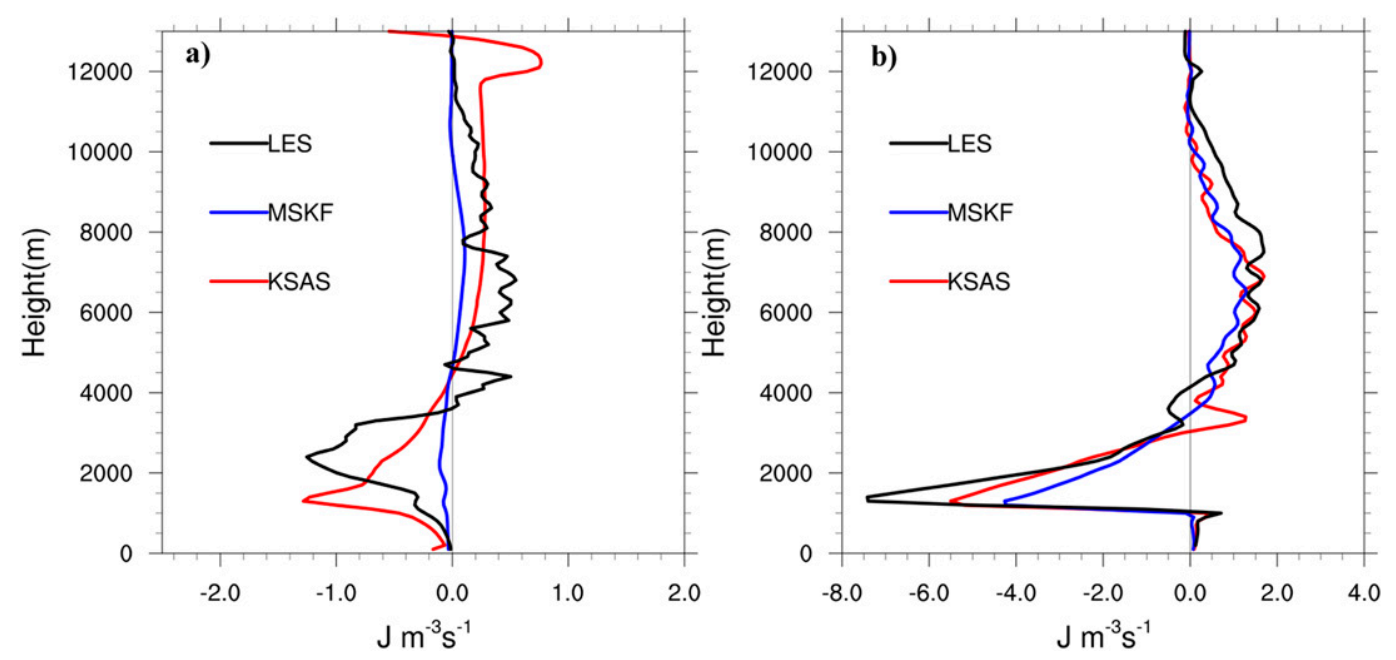

FIG. 1. Vertical profiles of the $h$ tendencies $\bar{\rho}(\partial \bar{h} / \partial t)$ due to (a) the subgrid convection and (b) the resolved motion in the MSKF (blue), KSAS runs (red), and the coarse-grained LES (black) at 3-km resolution averaged over $0-30 \mathrm{~min}$.

Note that the tendencies due to the subgrid turbulent mixing scheme and the shallow convection in the MSKF scheme are negligible compared with the convective tendency.

Figure 1b shows the vertical profiles of the $h$ tendencies due to the resolved motion in the MSKF and KSAS runs in comparison with the coarse-grained LES results [Eq. (4)], at 3-km resolution averaged over $0-30 \mathrm{~min}$. It can be seen that differences in subgrid parameterization can inevitably lead to different model solutions due to the interaction between the subgrid parameterization and resolved motion. This study focuses on the differences in various subgrid parameterizations. In this section, we examine the different characteristics of the MSKF and KSAS schemes, including the trigger, the computation of updraft and downdraft properties, and the closure assumption that controls the intensity of convection.

\section{a. Trigger}

The trigger of convection used in the two schemes is the criterion that determines when, where, and whether or not the convection parameterization is active at each grid point on the model domain. It plays a pivotal role in the development and evolution of parameterized subgrid convection (Kain and Fritsch 1992; Stensrud and Fritsch 1994).

Figure 2 shows cumulative convective precipitation from the KSAS and MSKF schemes at the start $(t=5 \mathrm{~s})$ and after $30 \mathrm{~min}$. In the idealized simulation, convection was initiated by a thermal bubble with a maximum potential temperature perturbation of $3 \mathrm{~K}$. At the start $(t=5 \mathrm{~s})$, it is surprising that convections were triggered everywhere except for the thermal bubble in the KSAS run (Fig. 2a), which is not physically possible. After $15 \mathrm{~min}$, convection around the bubble was triggered in the KSAS run (data not shown). At $t=30 \mathrm{~min}$, the distribution of convective precipitation was significantly different from that in the MSKF run (Figs. 2d,f). In addition, gridscale precipitation was not spatially consistent with convective precipitation (Figs. $2 \mathrm{~d}$ and $4 \mathrm{a}$ ). In the MSKF run, it is physically reasonable for convection to be triggered in the vicinity of the bubble (Fig. 2c). Gridscale precipitation and convective precipitation have a consistent structure in the MSKF run (Figs. $2 \mathrm{f}$ and $4 \mathrm{c}$ ). The gridscale precipitation in LES (no subgrid precipitation) depicts a more detailed structure compared to the $3-\mathrm{km}$ runs (Fig. $4 \mathrm{~d}$ ).

Next, we provide the reasons why the triggers of the two schemes behave differently. The formulation of the trigger in the MSKF scheme was designed by Fritsch and Chappell (1980) and tested initially by Kain and Fritsch (1992). Starting at the surface, the updraft source layer (USL) includes adjacent layers, with a total depth of at least $60 \mathrm{hPa}$. The parcel properties are mass-weighted mixed over the USL. Then, the mixed parcel is lifted without mixing with environmental air to its lifting condensation level (LCL), where an extra perturbation as a function of the gridscale vertical velocity is added. Thus, the stability of a parcel at the LCL largely depends on the gridscale ascent in the MSKF scheme. An extra temperature perturbation $\Delta T_{v}$ that depends on the gridscale forcing is defined as

$$
\Delta T_{v}=k\left[w_{g}-c(z)\right]^{1 / 3},
$$

where $k=4.64 \mathrm{~K} \mathrm{~s}^{1 / 3} \mathrm{~m}^{-1 / 3}, w_{g}$ is the resolved vertical velocity at the LCL, which is obtained by height-weighted averaging over two adjacent model levels to LCL, and $c(z)$ is the threshold vertical velocity. If the resulting temperature is less than the environmental value (i.e., $T_{\mathrm{LCL}}+\Delta T_{v}<T_{\mathrm{ENV}}$ ), the base of the USL is shifted to one model level higher, and the above procedure is repeated for a new potential USL. If the temperature of the perturbed parcel is greater than that of the environment (i.e., $T_{\mathrm{LCL}}+\Delta T_{v} \geq T_{\mathrm{ENV}}$ ), the parcel would be a candidate for deep convection. If the parcel can further rise a minimum height above its LCL (e.g., $300 \mathrm{hPa}$ ), triggering occurs. There is some evidence that the temperature perturbation to apply in this situation is related to large-scale dynamical 

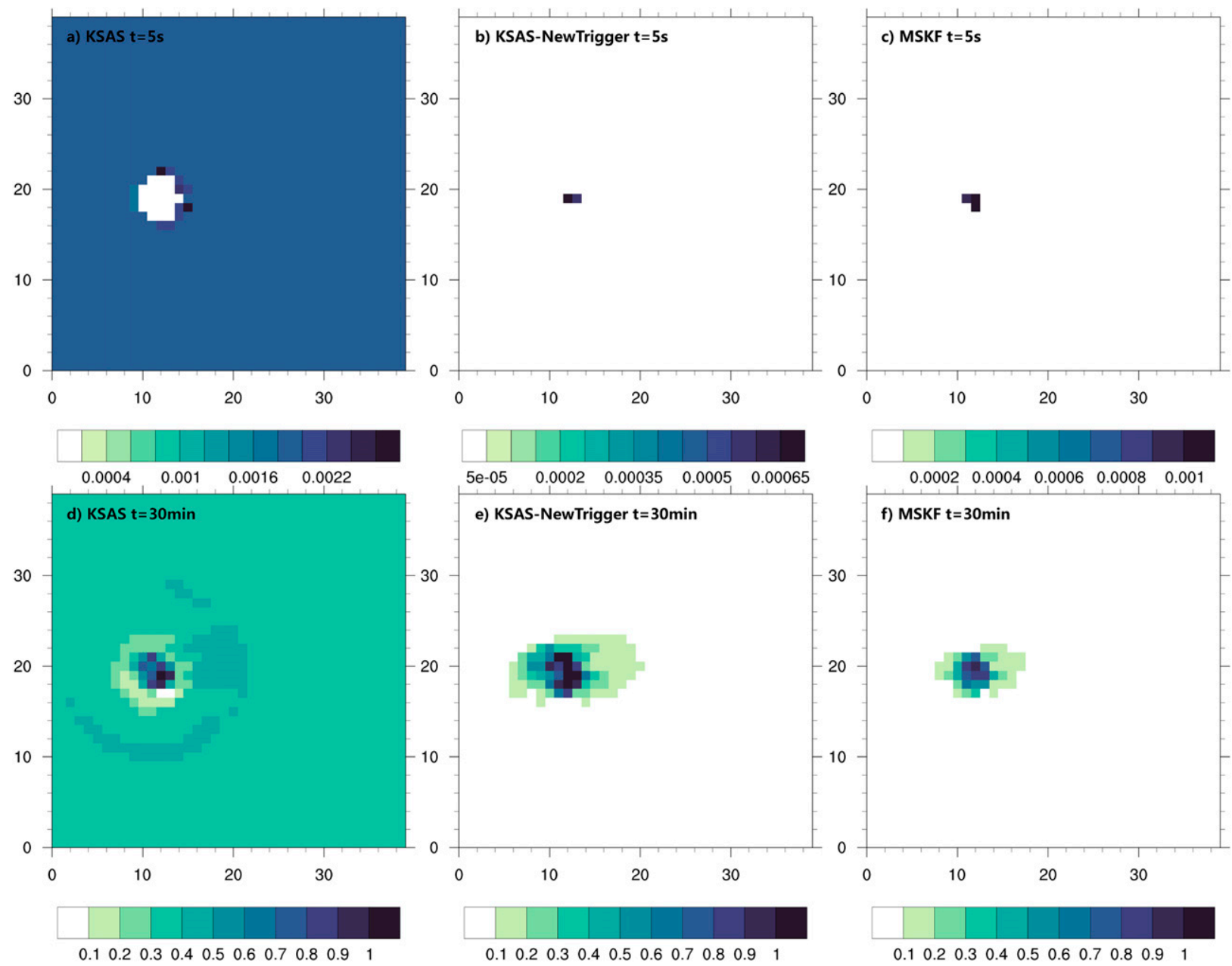

FIG. 2. Cumulative convective precipitation (mm) at (top) $t=5 \mathrm{~s}$ and (bottom) $t=30 \mathrm{~min}$ for (a),(d) KSAS; (b),(e) KSAS with the modified trigger; and (c),(f) the MSKF scheme.

forcing (Chen and Orville 1980), but a quantitative relationship between the two has not been established. In cases of subgrid convection without sufficiently resolved updraft (e.g., local thermal convection under the subsidence in the subtropical high), this convection trigger may be unrealistic.

The convection starting level (SL) in the KSAS run is defined as the location of local maximum $h$ in a model column between the surface and $700 \mathrm{hPa}$ level. The level of free convection (LFC) is defined as the level at which $h$ of the originating parcel is first larger than the saturation moist static energy of the local environment $\left(h>h^{*}\right.$, where $h^{*}=c_{p} T+L q_{v}^{*}+g z$; the asterisk denotes the saturation value) when a parcel moves aloft. A convective inhibition (CIN) factor is considered to suppress some unrealistic initiations of convection. The CIN factor in the KSAS run is represented by the pressure difference between the parcel's SL and its LFC. The larger the CIN factor, the more destabilization energy is required for lifting the parcel to initiate convection. When this CIN factor is larger than a threshold value, which is $180 \mathrm{hPa}$ multiplied by the average relative humidity between parcel SL and LFC ( $\left.\overline{\mathrm{RH}}^{(\mathrm{SL}, \mathrm{LFC})}\right)$, the KSAS scheme assumes that the destabilization energy of the parcel is not large enough to overcome negative buoyancy. When

$$
p_{\mathrm{SL}}-p_{\mathrm{LFC}}>\mathrm{CIN}_{\mathrm{th}} \times \overline{\mathrm{RH}}^{(\mathrm{SL}, \mathrm{LFC})},
$$

where $p_{\mathrm{SL}}$ and $p_{\mathrm{LFC}}$ are the pressures at the SL and LFC, respectively, subgrid convection will not be triggered. Kain and Fritsch (1992) referred to this type of triggering as a lifting depth trigger, and it is not a direct function of instantaneous dynamic forcing.

The vertical profiles of $h$ in the environment and bubble from the initial condition are shown in Fig. 3. It is noteworthy that the pressure difference between the parcel SL and the LFC in the environment is very small (Fig. 3a), and convection is very easy to trigger. In the bubble, the pressure difference is larger than that in the environment (Fig. 3b), suppressing the triggering of convection.

Differences in triggers can change the patterns in the early development of convection, leading to nonlinear changes in the subsequent evolution of convections (Kain and Fritsch 1992). To maintain physical consistency between the KSAS and 

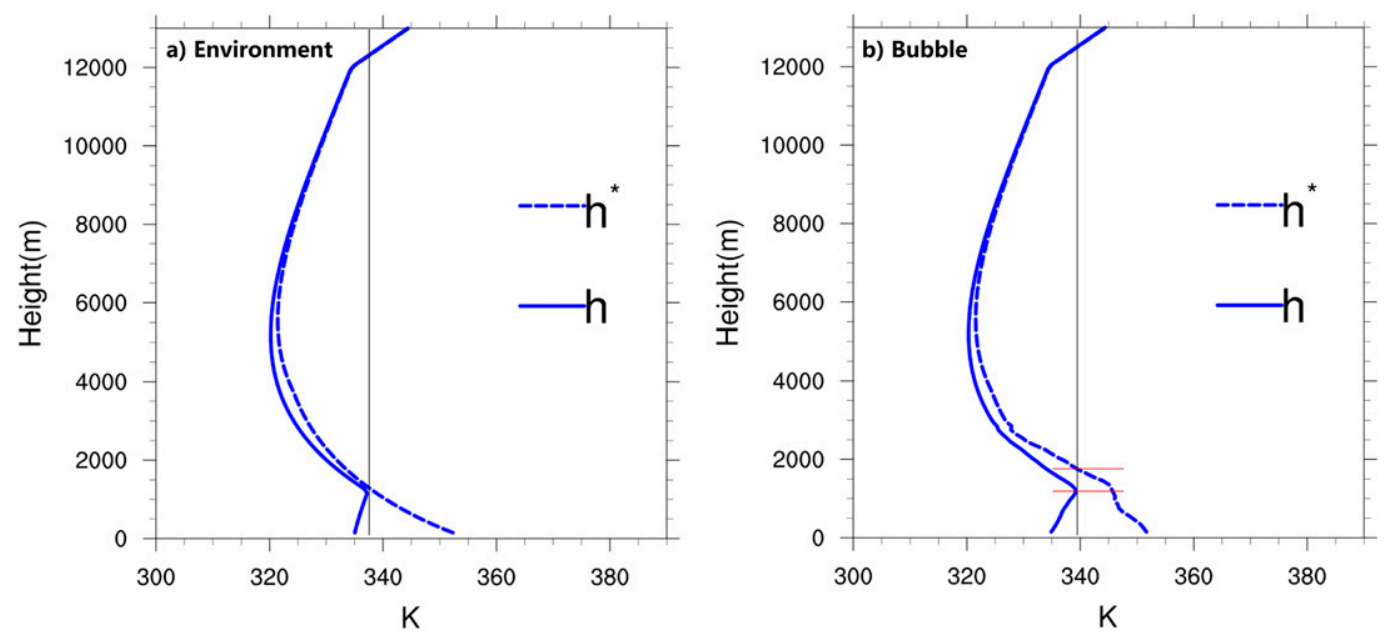

FIG. 3. Vertical profiles of moist static energy divided by $c_{p}$ in the (a) environment (a) and (b) bubble from the initial condition. The vertical solid line indicates the values used to determine the trigger of convection. The pressure difference between the SL (denoted by the horizontal red line below) and LFC (denoted by the horizontal red line above) represents the CIN factor in KSAS. The larger the CIN factor, the more difficult for convection to initiate. The bubble profile is near the center of the bubble.

MSKF schemes in terms of triggers, we changed the original trigger of the KSAS scheme. The original trigger in the KSAS scheme, based on the pressure difference, was changed to the criterion that gridscale vertical velocity $\bar{w}$ of the originating parcel at the LCL exceeds $0.01 \mathrm{~m} \mathrm{~s}^{-1}$. Hence, the new trigger is consistent with the MSKF trigger, at least in terms of its physical meaning, and both are a direct function of instantaneous dynamic forcing. Figure $2 b$ shows convective precipitation from the KSAS with a new trigger at $t=5 \mathrm{~s}$. The results are significantly different from those of the original trigger (Fig. 2a and b). After $30 \mathrm{~min}$, the distribution of convective precipitation from the KSAS with the modified trigger has a structure like that in the MSKF scheme (Figs. 2e,f). In addition, gridscale precipitation was spatially consistent with convective precipitation (Figs. 2e and 4b). The revised trigger in the KSAS scheme, using gridscale vertical velocity, exhibited behavior similar to that of the MSKF trigger.

The concept of triggering in both the MSKF and KSAS schemes depends on the model's grid size. Historically, all the two schemes were formulated based on assumptions that are only valid for a specific range of resolutions. The trigger in the KSAS scheme, as developed for the GFS, refers to the onset of an ensemble of convection as a whole rather than the actual physical trigger of each convection element on the subgrid scale. It is, therefore, assumed in the KSAS scheme that subgrid random perturbations (such as warm bubbles) exist in a grid box to trigger subgrid convection under an environment with convective instability. Using the vertical profile of $h$ in the KSAS scheme, the lifting depth trigger may be more appropriate for coarse resolution models. However, in convectionpermitting models, it is typically assumed that no enough perturbations exist in a small grid box to trigger convection; convection must be triggered by resolved dynamic forcing. In contrast, the MSKF trigger includes the effect of gridscale dynamic forcing. It thus is more suitable than the original
KSAS trigger at convection-permitting resolutions in an NWP context.

\section{b. Cloud model}

The central problem of a mass-flux-based convection scheme, like the MSKF and KSAS schemes, is the determination of the convective mass flux, $M$. Convective mass flux is often separated into two parts, one for the vertical profile $\eta(z)$ and the other for a time-dependent amplitude $M_{B}(t)$ :

$$
M=\eta(z) M_{B}(t) .
$$

In general, the vertical profile $\eta(z)$ is determined by the "cloud model" (e.g., Yano and Plant 2015). The amplitude $M_{B}(t)$ (usually defined at the cloud base) is defined by the "closure," which will be discussed in section 3a(1). The cloud model is based on the steady-state assumption that treats the subgrid-scale convective processes diagnostically rather than prognostically. This assumption suggests that fast subgrid-scale processes (not in equilibrium against the large-scale forcing) are neglected and that the subgrid-scale processes evolve in the balance against a given large-scale forcing. Note that the steady-state assumption is more valid when the grid box is large enough to contain all cloud sizes and clouds in different life cycle stages. As the grid sizes approach the scale of individual convective clouds, the assumption is no longer valid. The focus of this study is on the transient phase (first $30 \mathrm{~min}$ ) of convection, while the two tested convection schemes are still based on the steady-state assumption, which may lead to some deficiencies in the representation of convection.

The steady-state entraining/detraining plume model is used in both convection schemes. In the MSKF scheme, in which the full entrainment $(E)$ and detrainment $(D)$ rates (including updraft and downdraft denoted by subscripts $u$ and $d$ ) is specified, and the cloud model is written as 

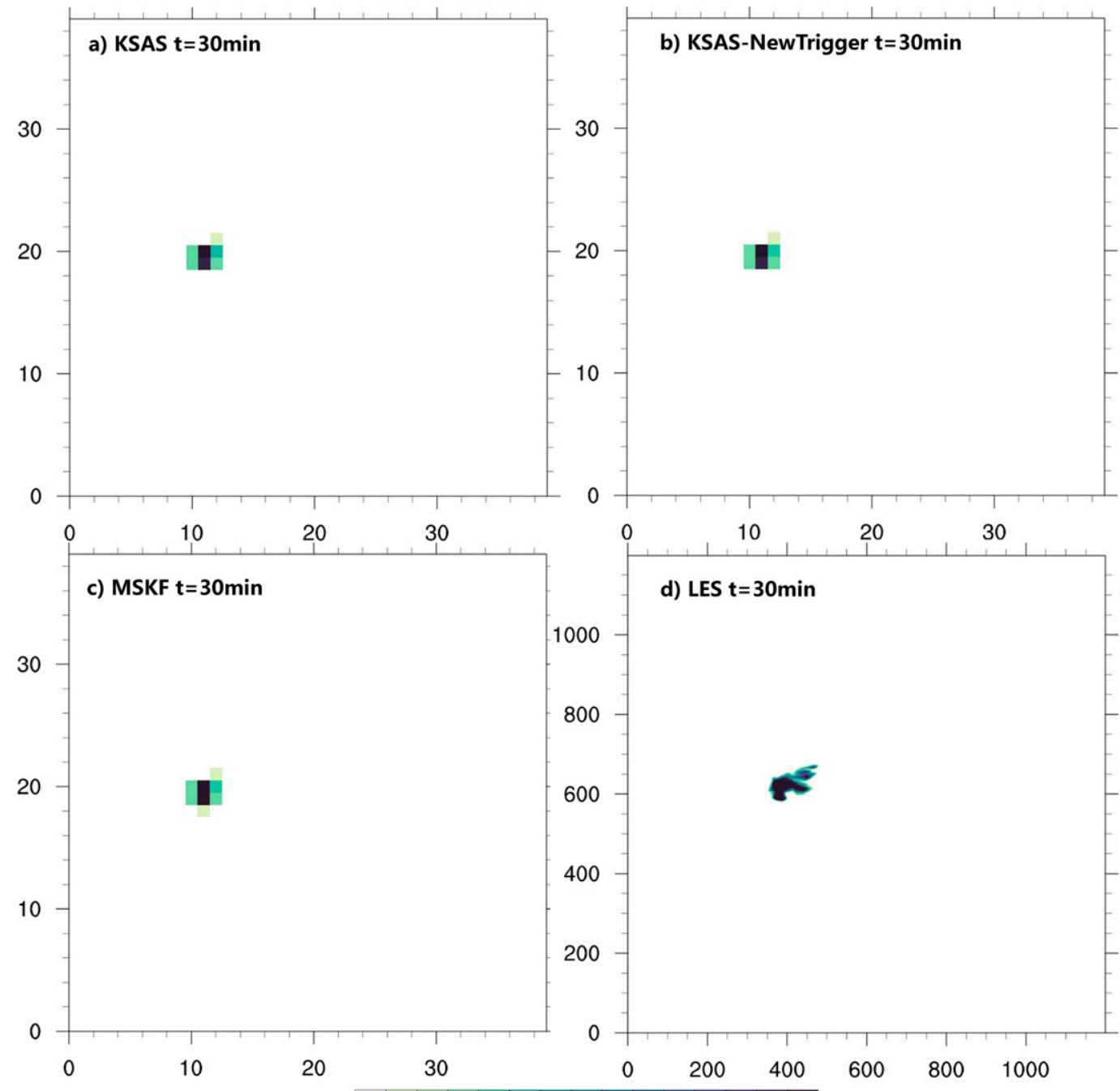

0.511 .522 .533 .544 .555 .566 .57

FIG. 4. Cumulative gridscale precipitation (mm) at $t=30 \mathrm{~min}$ for (a) KSAS, (b) KSAS with the modified trigger, (c) the MSKF scheme, and (d) LES.

$$
\frac{\partial M_{u, d}}{\partial z}=E_{u, d}-D_{u, d}
$$

The KSAS scheme, on the other hand, uses the fractional entrainment and detrainment rates, defined as $\varepsilon_{u, d}=E_{u, d} / M_{u, d}$, $\delta_{u, d}=D_{u, d} / M_{u, d}$, and uses the variable separation shown in Eq. (7); thus, the cloud model can be written in the form of a normalized mass-flux vertical profile:

$$
\frac{1}{\eta_{u, d}} \frac{\partial \eta_{u, d}}{\partial z}=\varepsilon_{u, d}-\delta_{u, d} .
$$

Once the (fractional) entrainment and detrainment rates are specified, the corresponding mass-flux profile $[\eta(z)] M$ can be determined by vertically integrating [Eq. (9)] Eq. (8).

The LES coarse-grained updraft/downdraft mass flux is calculated using $M_{u, d}=\rho a_{u, d}\left(w_{u, d}-\bar{w}\right)$, where $a_{u}\left(a_{d}\right)$ is the fractional area of the cloudy updraft (downdraft), $w_{u}\left(w_{d}\right)$ vertical velocity of cloudy updraft (downdraft), $\bar{w}$ the averaged vertical velocity over $3 \mathrm{~km} \times 3 \mathrm{~km}$ subdomain, and $\rho$ the density. In this study, the buoyant cloud core decomposition used a sampling criterion, in which the cloudy updraft is defined as the LES grid points that contain cloud water and ice $\left(q_{c}+q_{i}>0\right)$ and are positively buoyant $\left(\theta_{v}-\bar{\theta}_{v}>0\right)$, with $\theta_{v}$ denoting the virtual potential temperature, and the overbar denoting the horizontal average over the subdomain. Because the downdraft is usually assumed to be driven by the evaporation of precipitating water in parameterizations, a different sampling criterion $\left(q_{r}>1 \mathrm{~g} \mathrm{~kg}^{-1}\right.$ and $w_{d}<0$, with $q_{r}$ denoting the rainwater mixing ratio) is used to define the downdraft. It should be noted that the sampling criterion has no unique optimal values, and the coarse-grained LES results derived from the conditional sampling may have some uncertainties. 

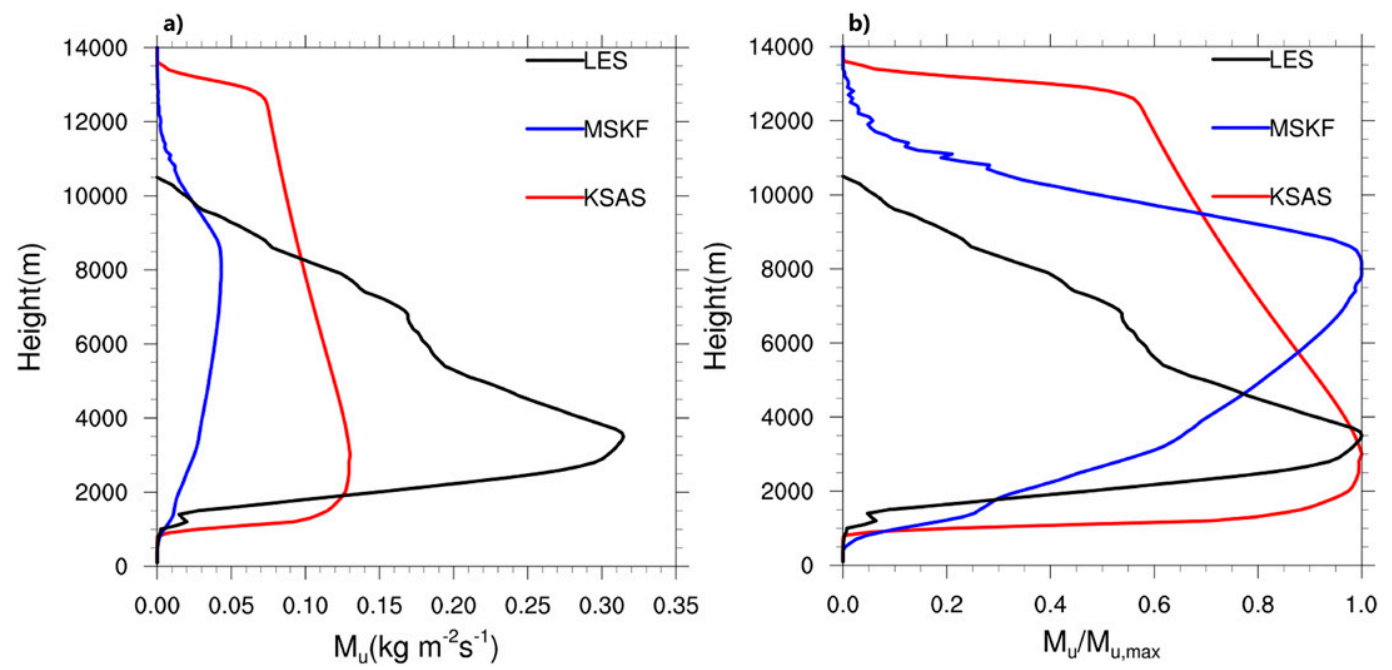

FIG. 5. Vertical profiles of (a) updraft mass flux $M_{u}$ and (b) the normalized by respective maximum from KSAS, MSKF cloud models, and LES.

\section{1) UPDRAFT MASS FLUX}

Figure 5 shows the vertical profiles of updraft mass flux $M_{u}$ from the KSAS and MSKF schemes, compared to that from the LES. The vertical profiles of $M_{u}$ in the KSAS and MSKF schemes are seen to be very different from the coarse-grained LES (Fig. 5a). The issue of the amplitude of $M_{u}$ is the topic of "closure" in section $3 \mathrm{a}(2)$. To isolate the cloud model, the $M_{u}$ profiles normalized by their maximums are shown in Fig. 5b. The peak of $M_{u}$ was found at the height of $3 \mathrm{~km}$ in the KSAS run, while the $M_{u}$ in the MSKF run gradually increased with height until it was maximal at about $8 \mathrm{~km}$. In the KSAS run, the detrainment gradually depleted the $M_{u}$ from 3 to $14 \mathrm{~km}$, resulting in a mass-flux profile with a weaker vertical gradient. Although the maximum $M_{u}$ in the KSAS run and LES are almost at the same height, of about $3.5 \mathrm{~km}$, the $M_{u}$ in the LES decreased with height more rapidly than that in the KSAS run.

Different formulations of entrainment and detrainment in the two schemes are responsible for the different vertical profiles of mass flux. In the KSAS scheme, the fractional entrainment rate of updraft $\varepsilon_{u}$ above the cloud base is specified as

$$
\varepsilon_{u}=\varepsilon_{0}\left(\frac{\bar{q}_{s}}{\bar{q}_{s, b}}\right)^{2}+10^{-4}(1-\mathrm{RH})\left(\frac{\bar{q}_{s}}{\bar{q}_{s, b}}\right)^{3},
$$

where $\varepsilon_{0}=0.1 / z_{\mathrm{LFC}}$ is the entrainment rate at the cloud base, $\mathrm{RH}$ is the environmental (gridbox mean) relative humidity, and $\bar{q}_{s}$ and $\bar{q}_{s, b}$ are the gridbox saturation specific humidity at the parcel level and the cloud base, respectively. Equation (10) indicates that a drier environment (lower RH) leads to an increase in entrainment. Below the cloud base, $\varepsilon_{u}$ is inversely proportional to height $z$ :

$$
\varepsilon_{u}=\frac{0.1}{z}
$$

The fractional detrainment rate $\delta_{u}$ of the updraft is vertically constant and equal to the entrainment rate $\varepsilon_{0}$ at the cloud base (LFC):

$$
\delta_{u}=\varepsilon_{0}=\frac{0.1}{z_{\mathrm{LFC}}} .
$$

Figure 6 shows the vertical profiles of entrainment rates $E_{u}$ and detrainment rates $D_{u}$ of the updraft mass flux from the KSAS and MSKF runs. In the KSAS run, $D_{u}$ decreases slightly with height, while $E_{u}$ is largest near the surface and decreased with height. It is the difference between $E_{u}$ and $D_{u}$, which determines how fast the mass flux decreases with height. The intersection of $E_{u}$ and $D_{u}$ in the KSAS (MSKF) run is at the height of $3 \mathrm{~km}(8 \mathrm{~km})$, which corresponds to the maximum $M_{u}$ in Fig. 5b.

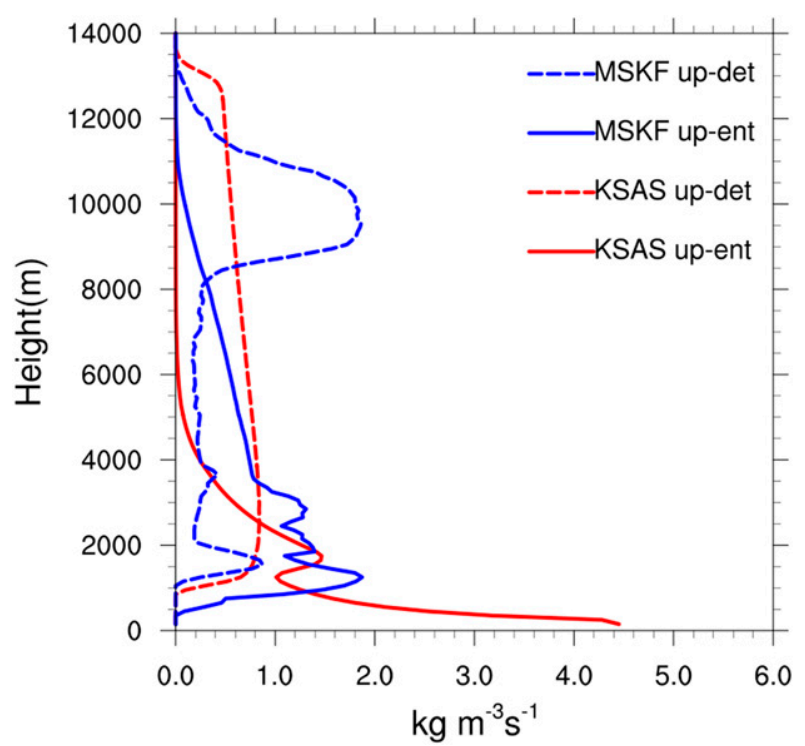

FIG. 6. Vertical profiles of (solid line) entrainment rates $E_{u}$ and (dashed line) detrainment rates $D_{u}$ of the updraft mass flux in KSAS (red) and MSKF (blue) schemes, averaged over 0-30 min. The magnitude is scaled by $10^{5}$. 

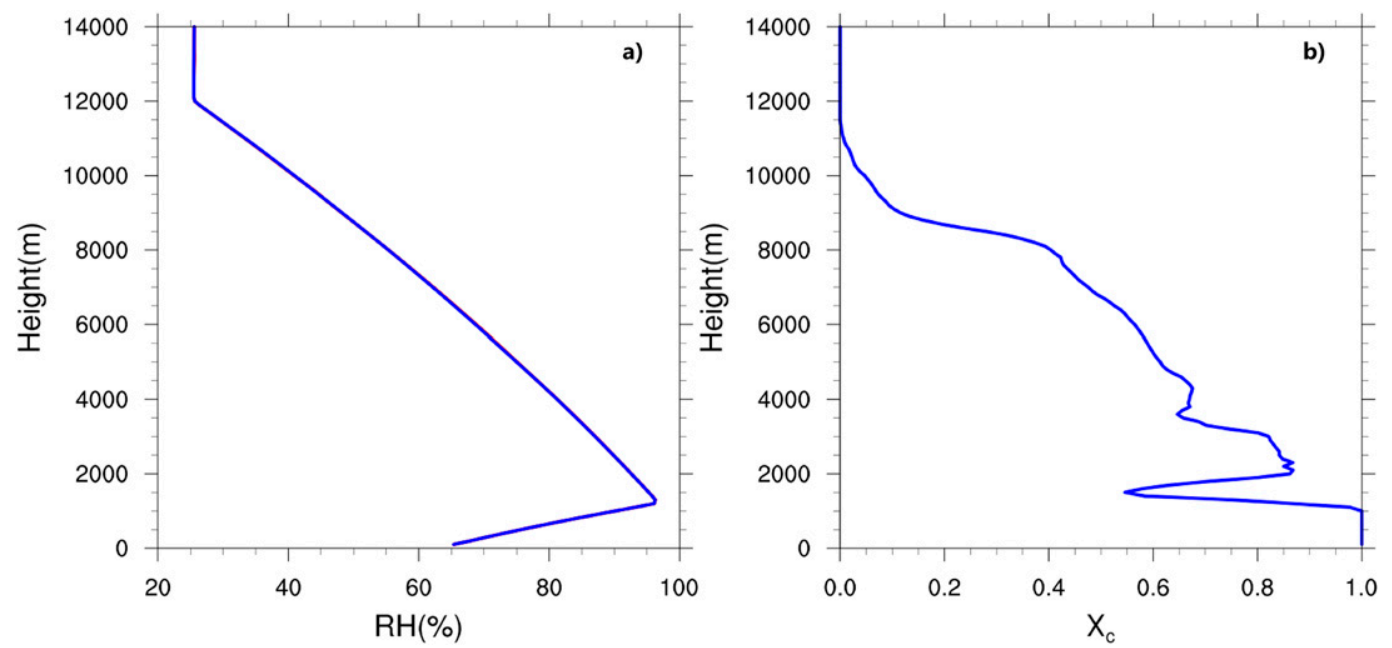

FIG. 7. Vertical profiles of (a) relative humidity (RH), and (b) the critical fraction of environmental air $\left(x_{c}\right)$ from the MSKF scheme averaged over the domain.

The formulation of entrainment and detrainment in the MSKF scheme is based on the buoyancy sorting theory (Raymond and Blyth 1986). In this theory, different mixtures of cloudy and environmental air are created with different degrees of mixing with the environment (measured by the fraction of environmental air $x$ ), and the probability of different mixtures is described by an assumed probability density function (PDF). Furthermore, based on the critical fraction $x_{c}$, defined as the fraction of environmental air mass that leads to neutral buoyancy, all negatively buoyant mixtures (i.e., mixtures with $x>x_{c}$ ) are assumed to detrain, while all positively buoyant mixtures (i.e., $x<x_{c}$ ) are entrained into the cloudy updraft. Therefore, the amount of entrained and detrained air is determined by $x_{c}$ and the assumed PDF. Although a Gaussian PDF was chosen in the standard MSKF formulation, the physical concept of the buoyancy sorting theory can be more clearly illustrated by assuming the simplest PDF: that all mixtures are equally likely to be generated (Bretherton et al. 2004). Based on the simplest PDF, the entrainment and detrainment rates are given as follows:

$$
\begin{aligned}
& E_{u}=\Delta M_{e} x_{c}^{2}, \\
& D_{u}=\Delta M_{e}\left(1-x_{c}\right)^{2},
\end{aligned}
$$

where $\Delta M_{e}$ is the amount of environmental air available for mixing. The entrainment and detrainment rates vary in opposite directions as functions of the critical fraction $x_{c}$. Physically, $x_{c}$ reflects the combined effect of environmental conditions and the buoyancy properties of cloudy air. The critical fraction $x_{c}$ increases both with the buoyancy of the cloudy updraft and with environmental relative humidity (de Rooy and Siebesma 2008). Figures $7 \mathrm{a}$ and $7 \mathrm{~b}$ show the vertical profiles of relative humidity $(\mathrm{RH})$ and $x_{c}$ from the MSKF run, respectively. The $\mathrm{RH}$ decreased with the height from 2 to $12 \mathrm{~km}$, which was accompanied by a decrease in $x_{c}$ with the height. As a result, $E_{u}$ $\left(D_{u}\right)$ decreased (increased) with height, based on Eqs. (13) and (14) (Fig. 6). However, the $E_{u}$ in the MSKF run decreases slower with height from 2 to $12 \mathrm{~km}$ than the $E_{u}$ in the KSAS run, resulting in $M_{u}$ reaching its maximum until about $8 \mathrm{~km}$.

Note that the above formulations of entrainment and detrainment, with significant differences, lead to different massflux profiles shown in Fig. 5. In an LES study, Böing et al. (2012) found that the mass-flux profile of deep convection mainly depends on detrainment. The absolute variations in detrainment are much larger than those of entrainment. Moreover, detrainment has a clear correlation with the critical fraction $x_{c}$. In particular, their LES results showed that detrainment rates increase with the decrease of $x_{c}$, which is consistent with the detrainment formulation in the MSKF scheme. In contrast, the constant fractional detrainment rate in the KSAS scheme is an apparent oversimplification.

Böing et al. (2012) also found that the relationship between entrainment rates and $x_{c}$ is much weaker than the one for detrainment and $x_{c}$, and that entrainment has a dependence on $\mathrm{RH}$ that increases with decreasing $\mathrm{RH}$. That is, entrainment decreases in a moister and more unstable environment. However, in the MSKF scheme, entrainment is a function of $x_{c}$; that is, if the environmental air is drier (corresponding to a smaller $x_{c}$ ), the rate of entrainment will be smaller. This behavior is opposite to the findings of Böing et al. (2012). The entrainment in the KSAS scheme described in Eqs. (10) and (11) exhibits sensitivity with respect to environmental RH and follows the $1 / z$ behavior, resulting in almost the same height of maximum $M_{u}$ as the LES. However, $M_{u}$ slowly decreased with height due to nearly constant detrainment (Figs. 5b and 6).

The abovementioned results from Böing et al. (2012) indicate that entrainment rates should strongly decrease with height, leading to a mass-flux profile with a large gradient and allowing for large values in the lower part of the cloud layer, and include an explicit dependence of entrainment rate on $\mathrm{RH}$, leading to more realistic sensitivities to environmental conditions. In fact, Bechtold et al. (2008) showed that the dependence on $\mathrm{RH}$ of the entrainment and detrainment rates has important consequences for the parameterization of convection and clearly 

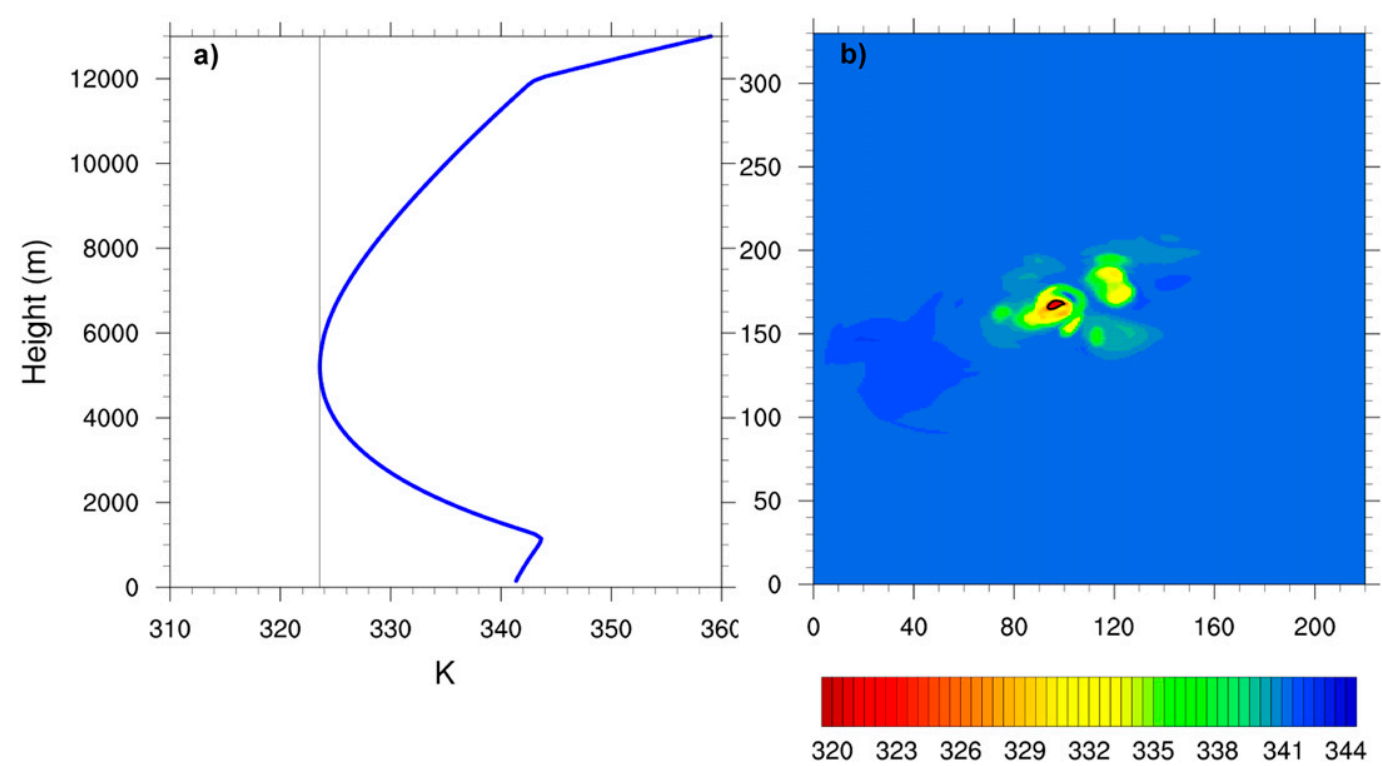

FIG. 8. (a) Vertical profile of domain-averaged equivalent potential temperature $\theta_{e}$ from LES at $t=30$ min and (b) horizontal distribution of $\theta_{e}$ at $z=150 \mathrm{~m}$. The vertical line in (a) and black contour in (b) correspond to the minimum $\theta_{e}$.

improves model performance. The significant correlation between the critical fraction $x_{c}$ and detrainment provides the possibility of taking $x_{c}$ as a key parameter. Apparently, the two schemes investigated in this study do not yet take these effects fully into account.

\section{2) DOWNDRAFT MASS FLUX}

The two convection schemes compared in this study include downdrafts in their formulations, which are based on several assumptions and have intrinsic uncertainties. One major uncertainty about downdraft is its starting level. In KSAS, the downdraft starting level is set at the minimum $h$ (with a very similar vertical structure of equivalent potential temperature $\left.\theta_{e}\right)$. Some studies inferred the downdraft starting level by analyzing the conserved thermodynamic variables during the moist adiabatic process. The vertical profile of $\theta_{e}$ in the environment of deep convection typically presents a minimum near $400-600 \mathrm{hPa}$. Air of low-value $\theta_{e}$ in the midtropospheric level often descends to the surface within downdrafts along a Lagrangian trajectory (Zipser 1969, 1977).

Figure 8a shows the vertical profile of domain-averaged $\theta_{e}$ and its minimum from LES, which is approximately $324 \mathrm{~K}$. Assuming the air with the minimum $\theta_{e}$ is conserved during its descent, the minimum $\theta_{e}$ corresponding to the downdraft can be found near the surface. Figure $8 \mathrm{~b}$ shows the horizontal distribution of $\theta_{e}$ near the surface $(z=150 \mathrm{~m})$ and contour of $324 \mathrm{~K}$, which corresponds to the minimum $\theta_{e}$ in the midtroposphere. This indicates that the assumption of the downdraft originating at the level of the minimum $h$ is justified, at least within the idealized simulation.

In the MSKF scheme, the origin level of the downdraft is specified as $150 \mathrm{hPa}$ above the USL. In the original KF scheme, the downdraft was assumed to originate from the minimum level $\theta_{e}$. However, Kain (2004) found that the variable starting level from the original algorithm leads to unphysical inconsistency of heating and drying in the low troposphere. Therefore, the start level was modified to be $150 \mathrm{hPa}$ above the USL (Kain 2004). This modification is consistent with observational evidence. For example, in less intense convective cases, downdrafts often originate just above the cloud base (e.g., Betts 1976; Johnson and Nicholls 1983).

Another uncertainty of the downdraft concerns the saturation of water vapor in the downdraft. In the KSAS scheme, a saturated downdraft is assumed. In the MSKF scheme, above the LCL, the air within the downdraft is saturated, while its relative humidity reduces by $20 \%$ per kilometer from the LCL to the surface. Yano and Plant (2015) examined the microphysical differences between the updraft and downdraft. He showed that within clouds, the updraft is driven by condensation of water vapor into cloud droplets, whereas the downdraft within rain is driven by the evaporation of rainwater, which results in an updraft air at saturation above the LCL and unsaturated downdraft, respectively. Also, the downdraft air becomes drier as it descends in a moist adiabat environmental lapse rate.

The magnitude of the downdraft, which must be determined at the starting level, is also uncertain. In the KSAS scheme, the downdraft mass flux is proportional to the updraft mass flux. The fraction is empirically determined by precipitation efficiency, which is a function of vertical wind shear (Fritsch and Chappell 1980). In the MSKF scheme, the dependence of precipitation efficiency on wind shear is excluded because of the difficulty of determining a quantitative relationship between them (Kain 2004). In the MSKF scheme, the magnitude of the downdraft mass flux at the top of the USL $\left(M_{d}^{\mathrm{USL}}\right)$ is defined as a fraction of the updraft mass flux $\left(M_{u}^{\mathrm{USL}}\right)$ according to the following: 

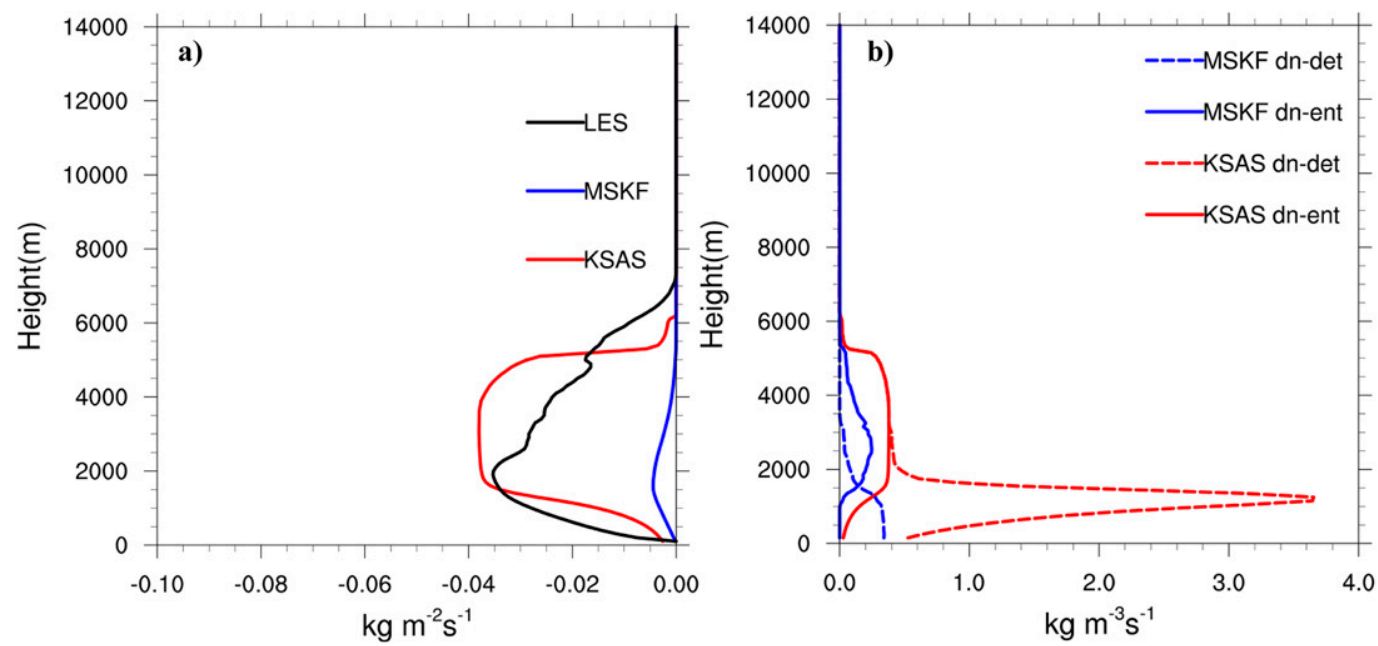

FIG. 9. (a) Vertical profiles of downdraft mass flux from KSAS, MSKF cloud models, and LES. (b) Vertical profiles of entrainment rates $E_{d}$ (solid line) and detrainment rates $D_{d}$ (dashed line) of the downdraft mass flux in KSAS (red) and MSKF (blue) schemes, averaged over 0-30 min. The magnitude of entrainment and detrainment rates is scaled by $10^{5}$.

$$
\frac{M_{d}^{\mathrm{USL}}}{M_{u}^{\mathrm{USL}}}=2\left(1-\overline{\mathrm{RH}}^{\mathrm{DSL}}\right),
$$

where $\overline{\mathrm{RH}}{ }^{\mathrm{DSL}}$ is the averaged relative humidity within the downdraft source layer (DSL). The DSL extends from the originating level of downdraft to the top of the USL. Therefore, downdraft mass flux is more (less) when the DSL is dry (moist). The magnitude of the downdraft mass flux is no longer dependent on the vertical wind shear. Instead, it is dependent on environmental humidity.

Figure 9a shows that the vertical profiles of downdraft mass flux $M_{d}$ from the KSAS, MSKF and LES runs. The vertical profiles of $M_{d}$ in KSAS and LES exhibit similar shapes, while the magnitude of $M_{d}$ in MSKF is much smaller. Note that the shape and magnitude of $M_{d}$ are sensitive to the sampling criterion. The sampling criterion $\left(q_{r}>1 \mathrm{~g} \mathrm{~kg}^{-1}\right.$ and $\left.w_{d}<0\right)$ was used to define the downdraft. Figure $9 \mathrm{~b}$ shows that the vertical profiles of entrainment rates $E_{d}$ and detrainment rates $D_{d}$ of the downdraft mass flux from the KSAS and MSKF runs. There are considerable differences between the two schemes in the profile and magnitude of the entrainment and detrainment rate. Different assumptions and formulations about entrainment and detrainment in the two schemes are summarized in Table 1.

\section{c. Closure}

Parameterization closure determines the intensity of convection in the parameterization. Convection is ultimately driven by buoyancy. The intensity of convection is controlled by vertically integrated convective buoyancy. Thus, a common method for developing closure is to define a vertically integrated quantity $I$, whose prognostic equation can be used to describe the change in intensity of convection, thereby closing the parameterization. The prognostic equation can be taken as the basis of prognostic closure (Pan and Randall 1998).
However, most operational convection parameterization schemes are still based on the quasi-equilibrium assumption (Arakawa and Schubert 1974). Although nonequilibrium convections are typically found under rapidly varying forcing (Davies et al. 2013), the validity of the quasi-equilibrium assumption for synoptic disturbances has been confirmed by many studies (Jones and Randall 2011; Yano and Plant 2012). Under the quasi-equilibrium assumption that the subgrid convective stabilization response is always in balance with gridscale destabilization forcing, the prognostic equation for the vertical integral of convective buoyancy becomes a diagnostic closure condition.

Yano and Plant (2015) derived a general formulation for closure and proposed a bulk vertical integral quantity:

$$
I=\int_{z_{B}}^{z_{T}} f(\eta, \varphi, \bar{\varphi}) d z,
$$

where $f$ is a function of large-scale variables $\bar{\varphi}$, convective variables $\varphi$, and the mass-flux profile $\eta$. The integral is performed from the cloud base $z_{B}$ to the cloud top $z_{T}$. The choice of $I$ is based on some physical considerations, and quantity $I$ has its own budget equation. In Arakawa and Schubert (1974), the choice of quantity $I$ is based on the analysis of the convective kinetic energy budget. In the KSAS scheme, the cloud work function $A$ is defined to describe the generation of convective kinetic energy:

$$
A=\int_{z_{B}}^{z_{T}} \eta b d z
$$

where $b$ is the convective buoyancy and is expressed in terms of moist static energy $h$. The quasi-equilibrium closure is specified as

$$
\frac{\partial A}{\partial t}=\left.\frac{\partial A}{\partial t}\right|_{\mathrm{LS}}+\left.\frac{\partial A}{\partial t}\right|_{\mathrm{CU}}=0
$$


where the subscript LS denotes the change rate of the cloud work function due to the large-scale process, the subscript CU denotes the change in the cloud work function due to convection.

If the cloud work function before convection adjustment is denoted by $A^{+}$, the large-scale destabilization forcing is counterbalanced by convective adjustment:

$$
\left.\frac{\partial A}{\partial t}\right|_{\mathrm{LS}}=\frac{A^{+}}{\tau}
$$

where $\tau$ is the convective adjustment time scale in which moist convection takes to adjust the environmental thermodynamic profiles to a quasi-equilibrium state. The stabilization effect due to the convection during a small time interval $\delta t$ can be further expressed by

$$
\left.\frac{\partial A}{\partial t}\right|_{\mathrm{CU}}=\frac{A^{*}-A^{+}}{M_{B}^{\prime} \delta t} M_{B},
$$

where $A^{*}$ is the cloud work function after the stabilization of the thermodynamic fields by an arbitrary amount of mass flux $M_{B}^{\prime}$. Based on the quasi-equilibrium closure (18), the cloudbase mass flux $M_{B}$ can be calculated using the following:

$$
M_{B}=\frac{A^{+}}{\tau} \frac{M_{B}^{\prime} \delta t}{A^{+}-A^{*}} .
$$

The MSKF scheme uses convective available potential energy (CAPE) as the closure quantity. CAPE is a physically relevant quantity for measuring moist convective instability. The intensity of convection is strongly correlated with the local CAPE. CAPE is defined as the vertical integral of buoyancy:

$$
\mathrm{CAPE}=\int_{z_{B}}^{z_{T}} b d z
$$

where $b$ is defined in terms of the difference between the virtual temperature $T_{v, u}$ in the convective updraft and the environmental virtual temperature $\bar{T}_{v}$ :

$$
b=g \frac{T_{v, u}-\bar{T}_{v}}{\bar{T}_{v}}
$$

CAPE can be considered as a special form of the cloud work function $A$ without the mass-flux profile $\eta$ (Yano and Plant 2015). To consider the effect of entrainment, CAPE is calculated for an entraining (diluted) parcel rather than an undiluted ascending parcel (Kain 2004). In practice, the convective virtual temperature $T_{v, u}$ is evaluated by an entraining parcel model, resulting in less buoyancy than the undiluted parcel ascent.

The MSKF closure relies on the assumption that at least $90 \%$ of CAPE, in a grid element is removed within an adjustment period. Similar to the KSAS closure [Eq. (18)], the quasi-equilibrium closure based on CAPE in the MSKF is specified as

$$
\frac{\partial \mathrm{CAPE}}{\partial t}=\left.\frac{\partial \mathrm{CAPE}}{\partial t}\right|_{\mathrm{LS}}+\left.\frac{\partial \mathrm{CAPE}}{\partial t}\right|_{\mathrm{CU}}=0 .
$$

If the CAPE before convection adjustment is denoted by $\mathrm{CAPE}^{+}$, the large-scale destabilization forcing is counterbalanced by convection over an adjustment period $\tau$ in the MSKF closure as the following:

$$
\left.\frac{\partial \mathrm{CAPE}}{\partial t}\right|_{\mathrm{LS}}=\frac{\mathrm{CAPE}^{+}}{\tau} .
$$

Equation (25) is used as the determinant of the updraft mass flux and corresponding downdraft mass flux until at least $90 \%$ of the $\mathrm{CAPE}^{+}$is eliminated. Note that the updraft, downdraft mass fluxes, and entrainment/detrainment fluxes are rearranged with the same incremental factor, and the vertical profile of mass flux described by the steady-state cloud model is not changed. Because the CAPE is an implicit function of the convective mass flux, the solution has to be found using the iteration algorithm.

\section{Discussion and summary}

In this study, an idealized LES of deep moist convection was used to assess two convection parameterization schemes and compare their differences in formulation and underlying assumptions at a typical convection-permitting grid size of $3 \mathrm{~km}$. It was found that the two parameterization schemes not only differ fundamentally in trigger function, cloud model, and closure assumptions but also disagree with the coarse-grained LES. These differences between the two schemes highlight the uncertainty in the parameterized representations of subgrid convection. The origin of the uncertainty can be traced back to the early history of the two schemes' development.

When the two convection schemes were developed with different underlying assumptions, they were evaluated using different baselines in terms of the effect of subgrid convection processes on the resolved dynamics (Yanai et al. 1973). Also, the evaluation of the two schemes was done separately in a model setup that convection was assumed to be unresolved and simulated by the convection scheme alone; there is no partition between resolved and unresolved convection. Later, when the schemes were adapted in models of the convection-permitting resolutions, they were evaluated in terms of forecast/simulation metrics meteorological observations instead of the heating and drying profiles due to subgrid convection. Results from this study highlight the importance of establishing benchmarks using observations and LES to develop and evaluate convection parameterization schemes suitable for models at convectionpermitting resolutions (e.g., Khairoutdinov et al. 2009; Heinze et al. 2017; Louf et al. 2019; Stevens et al. 2020).

The differences and uncertainty in the two schemes' parameterization of subgrid convection also point to the lack of consensus on how to accurately parameterize subgrid-scale-dependent convection processes (e.g., entrainment and detrainment). Recently, progress in the physical understanding of entrainment and detrainment has been made, which may improve future parameterizations. Detrainment has a clear correlation with the critical fraction $x_{c}$ and increases with a decrease in $x_{c}$. The formulation of the detrainment rate in the MSKF scheme depends on $x_{c}$, while the constant fractional detrainment rate in the KSAS scheme is a clear oversimplification. Results from previous LES studies (e.g., Böing et al. 2012; de Rooy et al. 2013) and cloud-resolving modeling studies (e.g., Derbyshire et al. 2004, 2011) show that the entrainment increases as the environmental relative humidity 
decreases. The entrainment will decrease in a moister and more unstable environment. However, in the MSKF scheme, the entrainment rate will be smaller if the environmental air is drier. This behavior of the MSKF scheme is opposite to that of the entrainment formulation in the KSAS scheme. The lack of agreement in the formulations of the entrainment and detrainment rates represents the intrinsic uncertainty in the parameterization representation of mass-flux profiles in both schemes. This study also found that the triggering method in both the MSKF and KSAS schemes depends on the model's grid size. The trigger in the MSKF scheme, including the effect of gridscale dynamic forcing, is more suitable than the one in the KSAS scheme at convection-permitting resolutions.

It is worth emphasizing that the two schemes compared in this study, despite of being scale-adaptive at convection-permitting resolutions, are formulated using the quasi-equilibrium assumption that the subgrid convective stabilization response is always in balance with gridscale destabilization forcing. From a theoretical perspective, formulations and assumptions should be reconsidered under a more general nonequilibrium framework (e.g., prognostic closure and cloud model) for application in convection-permitting models (Gerard and Geleyn 2005; Gerard 2015; Tan et al. 2018). Such reconsideration has introduced the trend from diagnostic closures to prognostic closures (see, e.g., Pan and Randall 1998). For example, Park (2014) combined diagnostic convective plumes, prognostic subgrid convection organization and the feedback between them to formulate subgrid convection parameterization without using the quasi-equilibrium assumption in a unified convection scheme. We advocate that there is still a need to use LES or observations to establish benchmarks with consensuses for evaluating advanced convection schemes based on the general nonequilibrium framework.

Acknowledgments. We thank two anonymous reviewers for their careful review of our manuscript and their many insightful comments and suggestions. This work was supported by the National Key Research and Development Program of China (2017YFC150190X, 2016YFE0109700) and the National Science Foundation of China (Grant 41975133).

\section{REFERENCES}

Arakawa, A., and W. H. Schubert, 1974: Interaction of a cumulus cloud ensemble with the large-scale environment, Part I. J. Atmos. Sci., 31, 674-701, https://doi.org/10.1175/15200469(1974)031<0674:IOACCE>2.0.CO;2.

—, J.-H. Jung, and C.-M. Wu, 2011: Towards unification of the multiscale modeling of the atmosphere. Atmos. Chem. Phys., 11, 3731-3742, https://doi.org/10.5194/acp-11-3731-2011.

Bechtold, P., M. Kohler, T. Jung, F. Doblas-Reyes, M. Leutbecher, M. J. Rodwell, F. Vitart, and G. Balsamo, 2008: Advances in simulating atmospheric variability with the ECMWF model: From synoptic to decadal time-scales. Quart. J. Roy. Meteor. Soc., 134, 1337-1351, https://doi.org/10.1002/qj.289.

- - - - - - - - - - - - , and —, 2014: Representing equilibrium and nonequilibrium convection in large-scale models. J. Atmos. Sci., 71, 734-753, https:// doi.org/10.1175/JAS-D-13-0163.1.

Benjamin, S. G., and Coauthors, 2016: A North American hourly assimilation and model forecast cycle: The Rapid Refresh.
Mon. Wea. Rev., 144, 1669-1694, https://doi.org/10.1175/ MWR-D-15-0242.1.

Betts, A. K., 1976: The thermodynamic transformation of the tropical subcloud layer by precipitation and downdrafts. J. Atmos. Sci., 33, 1008-1020, https://doi.org/10.1175/15200469(1976)033<1008:TTTOTT>2.0.CO;2.

Böing, S. J., A. P. Siebesma, J. D. Korpershoek, and H. J. J. Jonker, 2012: Detrainment in deep convection. Geophys. Res. Lett., 39, L20816, https://doi.org/10.1029/2012GL053735.

Bretherton, C. S., J. McCaa, and H. Grenier, 2004: A new parameterization for shallow cumulus convection and its application to marine subtropical cloud-topped boundary layers. Part I: Description and 1D results. Mon. Wea. Rev., 132, 864-882, https:// doi.org/10.1175/1520-0493(2004)132<0864:ANPFSC >2.0.CO;2.

Bryan, G. H., J. C. Wyngaard, and J. M. Fritsch, 2003: Resolution requirements for the simulation of deep moist convection. Mon. Wea. Rev., 131, 2394-2416, https://doi.org/10.1175/15200493(2003)131<2394:RRFTSO>2.0.CO;2.

Chen, C., and H. D. Orville, 1980: Effects of mesoscale convergence on cloud convection. J. Appl. Meteor., 19, 256-274, https://doi.org/ 10.1175/1520-0450(1980)019<0256:EOMCOC > 2.0.CO;2.

Davies, L., R. S. Plant, and S. H. Derbyshire, 2013: Departures from convective equilibrium with a rapidly-varying surface forcing. Quart. J. Roy. Meteor. Soc., 139, 1731-1746, https:// doi.org/10.1002/qj.2065.

de Rooy, W. C., and A. P. Siebesma, 2008: A simple parameterization for detrainment in shallow cumulus. Mon. Wea. Rev., 136, 560-576, https://doi.org/10.1175/2007MWR2201.1.

— , and Coauthors, 2013: Entrainment and detrainment in cumulus convection: An overview. Quart. J. Roy. Meteor. Soc., 139, 1-19, https://doi.org/10.1002/qj.1959.

Deardorff, J. W., 1980: Stratocumulus-capped mixed layers derived from a three-dimensional model. Bound.-Layer Meteor., 18, 495-527, https://doi.org/10.1007/BF00119502.

Derbyshire, S. H., I. Beau, P. Bechtold, J.-Y. Grandpeix, J.-M. Piriou, J.-L. Redelsperger, and P. M. M. Soares, 2004: Sensitivity of moist convection to environmental humidity. Quart. J. Roy. Meteor. Soc., 130, 3055-3079, https://doi.org/10.1256/qj.03.130.

, A. V. Maidens, S. F. Milton, R. A. Stratton, and M. R. Willett, 2011: Adaptive detrainment in a convective parameterization. Quart. J. Roy. Meteor. Soc., 137, 1856-1871, https://doi.org/10.1002/qj.875.

Fowler, L. D., M. C. Barth, and K. Alapaty, 2020: Impact of scaleaware deep convection on the cloud liquid and ice water paths and precipitation using the Model for Prediction Across Scales (MPAS-v5.2). Geosci. Model Dev., 13, 2851-2877, https:// doi.org/10.5194/gmd-13-2851-2020.

Fritsch, J. M., and C. F. Chappell, 1980: Numerical prediction of convectively driven mesoscale pressure systems. Part I: Convective parameterization. J. Atmos. Sci., 37, 1722-1733, https://doi.org/ 10.1175/1520-0469(1980)037<1722:NPOCDM > 2.0.CO;2.

Gerard, L., 2015: Bulk mass-flux perturbation formulation for a unified approach of deep convection at high resolution. Mon. Wea. Rev., 143, 4038-4063, https://doi.org/10.1175/MWR-D-15-0030.1.

_ , and J.-F. Geleyn, 2005: Evolution of a subgrid deep convection parametrization in a limited area model with increasing resolution. Quart. J. Roy. Meteor. Soc., 131, 2293-2312, https:// doi.org/10.1256/qj.04.72.

Grell, G. A., and S. R. Freitas, 2014: A scale and aerosol aware stochastic convective parameterization for weather and air quality modeling. Atmos. Chem. Phys., 14, 5233-5250, https:// doi.org/10.5194/acp-14-5233-2014.

Han, J., W. Wang, Y. C. Kwon, S.-Y. Hong, V. Tallapragada, and F. Yang, 2017: Updates in the NCEP GFS cumulus convection 
schemes with scale and aerosol awareness. Wea. Forecasting, 32, 2005-2017, https://doi.org/10.1175/WAF-D-17-0046.1.

Heinze, R., and Coauthors, 2017: Large-eddy simulations over Germany using ICON: A comprehensive evaluation. Quart. J. Roy. Meteor. Soc., 143, 69-100, https://doi.org/10.1002/qj.2947.

Hong, S.-Y., Y. Noh, and J. Dudhia, 2006: A new vertical diffusion package with an explicit treatment of entrainment processes. Mon. Wea. Rev., 134, 2318-2341, https://doi.org/10.1175/MWR3199.1.

Honnert, R., V. Masson, and F. Couvreux, 2011: A diagnostic for evaluating the representation of turbulence in atmospheric models at the kilometric scale. J. Atmos. Sci., 68, 3112-3131, https://doi.org/10.1175/JAS-D-11-061.1.

Huang, W., J.-W. Bao, X. Zhang, and B. Chen, 2018: Comparison of the vertical distributions of cloud properties from idealized extratropical deep convection simulations using various horizontal resolutions. Mon. Wea. Rev., 146, 833-851, https:// doi.org/10.1175/MWR-D-17-0162.1.

Johnson, R. H., and M. Nicholls, 1983: A compositive analysis of the boundary layer accompanying a tropical squall line. Mon. Wea. Rev., 111, 308-319, https://doi.org/10.1175/1520-0493(1983) $111<0308$ :ACAOTB $>2.0$. CO;2.

Jones, T. R., and D. A. Randall, 2011: Quantifying the limits of convective parameterizations. J. Geophys. Res., 116, D08210, https://doi.org/10.1029/2010JD014913.

Kain, J. S., 2004: The Kain-Fritsch convective parameterization: An update. J. Appl. Meteor., 43, 170-181, https://doi.org/ 10.1175/1520-0450(2004)043<0170:TKCPAU > 2.0.CO;2.

__, and J. M. Fritsch, 1990: A one-dimensional entraining/ detraining plume model and its application in convective parameterization. J. Atmos. Sci., 47, 2784-2802, https://doi.org/ 10.1175/1520-0469(1990)047<2784:AODEPM>2.0.CO;2.

— and - 1992: The role of the convective "trigger" function in numerical forecasts of mesoscale convective systems. Meteor. Atmos. Phys., 49, 93-106, https://doi.org/10.1007/BF01025402.

Khairoutdinov, M. F., S. K. Krueger, C.-H. Moeng, P. A. Bogenschutz, and D. A. Randall, 2009: Large-eddy simulation of maritime deep tropical convection. J. Adv. Model. Earth Syst., 1 (15), https://doi.org/10.3894/JAMES.2009.1.15.

Kwon, Y. C., and S.-Y. Hong, 2017: A mass-flux cumulus parameterization scheme across gray-zone resolutions. Mon. Wea. Rev., 145, 583-598, https://doi.org/10.1175/MWR-D-16-0034.1.

Louf, V., C. Jakob, A. Protat, M. Bergmann, and S. Narsey, 2019: The relationship of cloud number and size with their largescale environment in deep tropical convection. Geophys. Res. Lett., 46, 9203-9212, https://doi.org/10.1029/2019GL083964.

Moeng, C.-H., P. P. Sullivan, M. F. Khairoutdinov, and D. A. Randall, 2010: A mixed scheme for subgrid-scale fluxes in cloud-resolving models. J. Atmos. Sci., 67, 3692-3705, https:// doi.org/10.1175/2010JAS3565.1.

Pan, D.-M., and D. A. Randall, 1998: A cumulus parameterization with prognostic closure. Quart. J. Roy. Meteor. Soc., 124, 949981, https://doi.org/10.1002/qj.49712454714.

Park, S., 2014: A unified convection scheme (UNICON). Part I: Formulation. J. Atmos. Sci., 71, 3902-3930, https://doi.org/ 10.1175/JAS-D-13-0233.1.

Raymond, D. J., and A. M. Blyth, 1986: A stochastic mixing model for nonprecipitating cumulus clouds. J. Atmos. Sci., 43, 2708-2718, https://doi.org/10.1175/1520-0469(1986)043<2708: ASMMFN $>2.0 . \mathrm{CO} ; 2$.

Siebesma, A. P., and J. W. M. Cuijpers, 1995: Evaluation of parametric assumptions for shallow cumulus convection. J. Atmos. Sci., 52, 650-666, https://doi.org/10.1175/1520-0469(1995) $052<0650$ :EOPAFS $>2.0$.CO;2.
Skamarock, W. C., and J. B. Klemp, 2008: A time-split nonhydrostatic atmospheric model for Weather Research and Forecasting applications. J. Comput. Phys., 227, 3465-3485, https://doi.org/10.1016/j.jcp.2007.01.037.

Stensrud, D. J., and J. M. Fritsch, 1994: Mesoscale convective systems in weakly forced large-scale environments. Part III: Numerical simulations and implications for operational forecasting. Mon. Wea. Rev., 122, 2084-2104, https://doi.org/ 10.1175/1520-0493(1994)122<2084:MCSIWF>2.0.CO;2.

Stevens, B., and Coauthors, 2020: The added value of large-eddy and storm-resolving models for simulating clouds and precipitation. J. Meteor. Soc. Japan, 98, 395-435, https://doi.org/ 10.2151/jmsj.2020-021.

Tan, Z., C. M. Kaul, K. G. Pressel, Y. Cohen, T. Schneider, and J. Teixeira, 2018: An extended eddy-diffusivity mass-flux scheme for unified representation of subgrid-scale turbulence and convection. J. Adv. Model. Earth Syst., 10, 770-800, https://doi.org/10.1002/2017MS001162.

Thompson, G., R. M. Rasmussen, and K. Manning, 2004: Explicit forecasts of winter precipitation using an improved bulk microphysics scheme. Part I: Description and sensitivity analysis. Mon. Wea. Rev., 132, 519-542, https://doi.org/10.1175/15200493(2004)132<0519:EFOWPU>2.0.CO;2.

,-- , and — 2008: Explicit forecasts of winter precipitation using an improved bulk microphysics scheme. Part II: Implementation of a new snow parameterization. Mon. Wea. Rev., 136, 5095-5115, https://doi.org/10.1175/2008MWR2387.1.

Weisman, M. L., and J. B. Klemp, 1982: The dependence of numerically simulated convective storms on vertical wind shear and buoyancy. Mon. Wea. Rev., 110, 504-520, https://doi.org/ 10.1175/1520-0493(1982)110<0504:TDONSC >2.0.CO;2.

_ , and R. Rotunno, 2000: The use of vertical wind shear versus helicity in interpreting supercell dynamics. J. Atmos. Sci., 57, 1452-1472, https://doi.org/10.1175/1520-0469(2000)057<1452: TUOVWS $>2.0 . \mathrm{CO} ; 2$.

Yanai, M., S. Esbensen, and J.-H. Chu, 1973: Determination of bulk properties of tropical cloud clusters from large-scale heat and moisture budgets. J. Atmos. Sci., 30, 611-627, https://doi.org/ 10.1175/1520-0469(1973)030<0611:DOBPOT > 2.0.CO;2.

Yano, J.-I., and R. Plant, 2012: Finite departures from convective quasi-equilibrium: Periodic cycle and discharge-recharge mechanism. Quart. J. Roy. Meteor. Soc., 138, 626-637, https://doi.org/ 10.1002/qj.957.

$\longrightarrow$, and -2015 : Closure. Parameterization of Atmospheric Convection, R. S. Plant and J. I. Yano, Eds., Vol. 1, World Scientific, 325-401.

Zhang, X., J.-W. Bao, B. Chen, and E. D. Grell, 2018: A three dimensional scale-adaptive turbulent kinetic energy scheme in the WRF-ARW Model. Mon. Wea. Rev., 146, 2023-2045, https://doi.org/10.1175/MWR-D-17-0356.1.

Zheng, Y., K. Alapaty, J. A. Herwehe, A. D. Del Genio, and D. Niyogi, 2016: Improving high-resolution weather forecasts using the Weather Research and Forecasting (WRF) Model with an updated Kain-Fritsch scheme. Mon. Wea. Rev., 144, 833-860, https://doi.org/10.1175/MWR-D-15-0005.1.

Zipser, E. J., 1969: The role of organized unsaturated convective downdrafts in the structure and rapid decay of an equatorial disturbance. J. Appl. Meteor., 8, 799-814, https://doi.org/ 10.1175/1520-0450(1969)008<0799:TROOUC >2.0.CO;2.

_- 1977: Mesoscale and convective-scale downdrafts as distinct components of squall-line circulation. Mon. Wea. Rev., 105, 1568-1589, https://doi.org/10.1175/1520-0493(1977)105<1568: MACDAD $>2.0 . \mathrm{CO} ; 2$. 